\title{
Correction to: Agonistic autoantibodies against adrenergic receptors correlating with antihypertensive therapy in long-standing diabetes type 2
}

\author{
Christoph Werner ${ }^{1}\left[\right.$ [ Nicolle Müller ${ }^{1}\left[\right.$. Ulrich Alfons Müller $^{1}$
}

Published online: 8 April 2019

(c) Springer-Verlag Italia S.r.l., part of Springer Nature 2019

\section{Correction to: Acta Diabetologica (2018) 55:301-303 https://doi.org/10.1007/s00592-018-1100-8}

Unfortunately, the conflict of interest statement was found incomplete in the original publication and now revised by the authors. The updated version is provided here.

Conflict of interest Investigations like patient recruitment, examination of patients, labor costs, statistics and writing manuscript were financed by house funds. The costs of determining the autoantibodies were carried by ERDE Diagnostics $\mathrm{GmbH}$. Based on these results, we initiated a larger study, substantially financed by Fresenius Medical Care.
Publisher's Note Springer Nature remains neutral with regard to jurisdictional claims in published maps and institutional affiliations.

The original article can be found online at https://doi.org/10.1007/ s00592-018-1100-8.

Christoph Werner

christoph.werner@med.uni-jena.de

1 Department of Internal Medicine III, Jena University

Hospital, Jena, Germany 